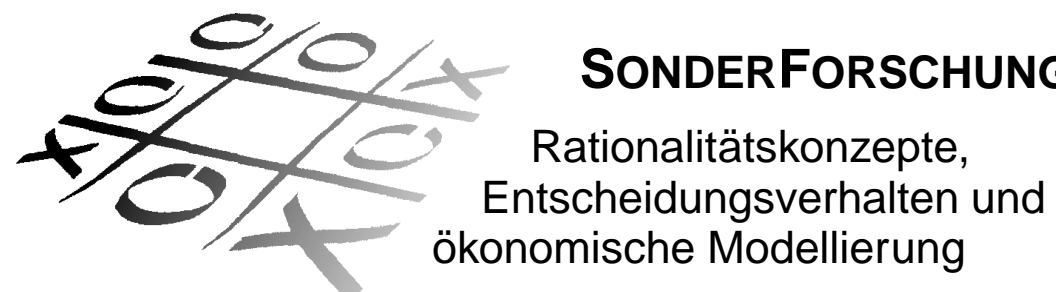

No. $01-21$

\title{
License Auctions and Market Structure
}

Jehiel, Phillipe*

and Moldovanu, Benny**

September 2000

We are grateful for many helpful comments made by the participants at the conference îAuctions and Market Structureî ,organized by the University of Mannheim, July 2000. Jehiel: ENPC, CERAS, 28 rue des Saints-Peres, 75007 Paris and UCL, London; je-hiel@enpc.fr; Moldovanu: Department of Economics, University of Mannheim, 68131 Mannheim; mold@pool.uni-mannheim.de

*ENPC, CERAS, Paris and UCL, London, email: jehiel@enpc.fr

**Department of Economics, University of Mannheim, Germany, email: mold@pool.uni-mannheim.de

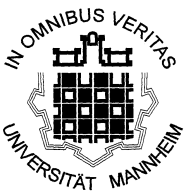

Universität Mannheim

L 13,15

68131 Mannheim 


\title{
License Auctions and Market Structure
}

\author{
Philippe Jehiel and Benny Moldovanu
}

September 19, 2000

\begin{abstract}
We analyze the interplay between license auctions and market structure in a model with several incumbents and several potential entrants. The focus is on the competitiveness induced by the number of auctioned licenses. Moreover, we study how the auction format affects the incentives for explicit or tacit collusion among incumbents. A crucial role is played by the relation between the number of incumbents and the number of licenses. If the number of incumbents is greater than the number of new licenses, we show that auctioning more licenses need not result in greater competitiveness If the number of licenses exceeds the number of incumbents, we display plausible conditions under which all incumbents get a license. Finally, we suggest a positive role for some auction formats in which the number of licenses is endogenously determined at the auction. We illustrate some results with examples drawn from European license auctions for 3G mobile telephony.
\end{abstract}

\section{Introduction}

Telecommunication, public transportation, electricity, water and gas were traditionally provided by (often monopolistic) state firms. It is now widely believed

${ }^{*}$ We are grateful for many helpful comments made by the participants at the conference "Auctions and Market Structure" ,organized by the University of Mannheim, July 2000.

$\dagger$ Jehiel: ENPC, CERAS, 28 rue des Saints-Peres, 75007 Paris and UCL, London; jehiel@enpc.fr; Moldovanu: Department of Economics, University of Mannheim, 68131 Mannheim; mold@pool.uni-mannheim.de 
that recent technological advances have undermined the "natural monopoly" argument which has been often advanced in defense of such market structures ${ }^{1}$. During the last two decades several industries have been radically transformed by the introduction of competition ${ }^{2}$. The liberalization was implemented in different ways, according to region and industry. In the telecommunication industry competition was created by licensing several private firms. There are, a priori, many ways to allocate licenses. For example, the allocation of first generation licenses for mobile telephony was made through lottery or through bureaucratic processes (so called "beauty contests"). Given that resale markets for licenses do not function well and are often subject to bureaucratic controls, and given that potential acquirers of licenses are better informed than regulators, it soon became clear that such methods lead to suboptimal allocations of licenses and that they do not generate substantial revenues. Further allocations of licenses were made through auctions (see McMillan, 1994 and McAfee and McMillan, 1996 for accounts of the US experience, and Klemperer, 2000 for the UK).

The main goal of most spectrum license auctions is economic efficiency, which implies that some weighted sum of consumers' and producers' surpluses should be maximized. Although it is invariably less advertised, revenue is also an important part of the agency's objective function because governments tend to prefer solutions that require less subsidies (or even provide budgetary surpluses).

The difficulty in achieving efficiency is due to the fact that consumers do not directly participate at spectrum auctions ${ }^{3}$. Moreover, ex-ante estimates of expected consumers' surplus in future market scenarios are difficult to make. Therefore, consumers' surplus does not play a natural role in shaping the auction's outcome, unless a regulatory agency provides a design that explicitly takes it into account. Since standard oligopoly models predict that in reasonable ranges both consumers' surplus and overall efficiency increase with increased competition among firms, the creation of sufficient market competition becomes a proxy goal that can be more

\footnotetext{
${ }^{1}$ The argument has been first articulated by John Stuart Mill in 1848: "It is obvious, for example, how great an economy of labor would be obtained if London were supplied by a single gas or water company instead of the existing plurality... Were there only one establishment, it could make lower charges consistently with obtainig the rate of profit now realized. (Mill 1926, p.143)"

${ }^{2}$ In many countries, competition has been accompanied by the creation of powerful, industry specific regulatory agencies.

${ }^{3}$ Another, more technical hurdle is presented by the fact that, in complex situations fitting well some spectrum auction environments, multi-unit efficient auctions simply do not exist and second-best mechanisms are not yet known (see Jehiel and Moldovanu, 1998).
} 
or less successfully implemented by the regulatory agency. Of course, entry cannot be efficiently extended without limit since infrastructure costs are very high.

The difficulty in achieving more competitive industries by licensing new firms is due to the fact that earlier allocations of licenses have already established incumbents operating according to some previous technological standard. Potential new entrants (i.e., firms that do not already operate a network) face two handicaps: 1) The fixed cost of setting up a network (say of antennae and relays) is very large. In contrast, a substantial part of the incumbents' fixed costs are already sunk, since they can use parts of their already existing facilities. 2) Incumbents are also driven by entry pre-emption motives which translate into increased willingness to pay for new licenses.

Excellent examples are provided by the British, Dutch and German license auction for "third generation (3G)" mobile telephony ${ }^{4}$. First generation networks offered simple analogue voice telephony; current systems (2G) added some data services like fax and e-mail; $3 \mathrm{G}$ networks (using the UMTS standard) should be capable of providing transmission rates up to 2 Megabites per second, and thus the prospect of high-resolution video, multimedia, mobile office, virtual banking, and many other on-line services.

Both Germany and the UK have 4 incumbents offering $2 \mathrm{G}$ services ${ }^{5}$ according to the GSM standard, and various economic viability estimates, together with physical spectrum limitations implied that no more than 6 firms could be licensed. Licenses were awarded for 20 years in both countries, and resales were not allowed. Considerations about the "right" number of licenses played a major role in the design of both auctions. Holland has 5 GSM incumbents.

The UK designers considered first an auction for 4 licenses $^{6}$, but then settled on 5 , one more than the number of incumbents. The frequency capacities attached to each license were fixed ex-ante, but different licenses came with different capacities, and the largest license has been reserved for a new entrant. Hence, the UK design actively tried to level the playing field among incumbents and new entrants. This auction attracted 9 potential new entrants besides the 4 incumbents. In contrast, the Dutch designers did not recognize that reserving licenses for entrants is necessary, and sold exactly 5 licenses. That auction attracted one

\footnotetext{
${ }^{4}$ Our model will apply to examples from other industries, such as power generation (see for example Cameron, Cramton and Wilson, 1997)

${ }^{5}$ Some other firms buy services from incumbents and resell them, but do not have networks.

${ }^{6}$ The initial design called for a simultaneous auction followed by a sealed bid stage among the 5 last bidders on the 4 licenses. The merits of this "Anglo-Dutch" auction are discussed in Klemperer (2000).
} 
potential new entrant. The German design was more, since it allowed outcomes with 4, 5 or 6 licenses. Besides an endogenous number of licenses, the design also allowed for endogenous capacity endowments ${ }^{7}$. This is its main weakness, since, in principle, it allows incumbents to completely preempt entry by bidding for additional capacity. In a companion paper (Jehiel and Moldovanu, 2000) we analyze this specific design in more detail. The German auction attracted 3 potential new entrants.

It is interesting to note that, in all auctions mentioned above, all respective incumbents got licenses. While there was no entry in Holland, an entrant (unavoidably) bought the reserved license in the UK. There were two new entries in Germany, but the process by which the outcome was reacheed is amusing: after the stage where 6 firms were left in the auction (which equaled the maximal possible number of licenses and meant that the auction could end) and an aggregate bid of DM 63 billion, the incumbents continued to try to acquire additional capacity and hence, simultaneously, to reduce the number of available licenses. Faced with determined entrants and nervous investors, they ultimately gave up without any change in the physical outcome. But all firms were another DM 35 billion poorer !

It is instructive to recall here also the result of the October 1999 German auction of capacity to the 4 GSM incumbents. The auction covered 10 duplex packages $^{8}$. T-Mobil and Mannesmann, the first mobile operators in Germany, are much larger than two later entrants. Besides a need for additional capacity in congested areas, the large players were most likely driven by a preemptive motive. The auction was conducted in a simultaneous ascending format and proceeded as follows: After the first round, the high bidder on all 10 packages was Mannesmann, which offered DM 36.360.000 for each of the packages 1-5, DM 40.000.000 for each of the packages 6-9 (which, recall, are identical to packages 1-5), and DM 56.000.000 for the larger package 10. In the second round, T-Mobil bid $^{9}$ DM 40.010.000 on packages 1-5, and the auction closed. Here is what one of T-Mobil's managers said: "No, there were no agreements with Mannesmann. But Mannesmann's first bid was a clear offer. Given Game Theory, it was expected that they show what they want most." (Frankfurter Allgemeine Zeitung, October

\footnotetext{
${ }^{7}$ Bids were made on 12 spectrum packages. A firm must acquire at least two packages in order to be licensed, but can acquire up to three packages.

${ }^{8}$ The first nine packages were identical, consisting of $2 \times 1 \mathrm{MHz}$, and the tenth consisted of $2 \times 1.4 \mathrm{MHz}$.

${ }^{9}$ Minimum increments had to be $10 \%$ of the last high bid.
} 
29, 1999, p.13)

In this paper we consider a situation in which several incumbents are already present in the market. A regulatory agency sells one or more licenses. It can determine the number of auctioned licenses and some features of the auction format. Potential acquirers of new licenses include the incumbents ${ }^{10}$ and entrants who are not yet present in the market. The downstream competition among licensed firms is modeled via a reduced-form industry profit function. This modeling approach implies that values for licenses are endogenous, and depend on the final number of licensed firms ${ }^{11}$.

For simplicity, but also in order to isolate the effect of market structure considerations, we assume that there are no informational asymmetries among the potential acquirers.

We focus on two objectives for the regulatory agency: the degree of competitiveness in the industry and the revenue generated by the auction. The degree of competitiveness is measured by the number of licensed firms after the auction (that is, the number of incumbents augmented by the number of entrants who acquire a license $)^{12}$.

The paper is organized as follows: In Section 2 we describe the underlying IO model. In Section 3 we analyze a one-license auction with $n$ incumbents, and the incumbents' incentives to collude. In Section 4 we study auctions for several licenses (with possible supply uncertainty). We also study an auction in which the number of licenses is endogenously determined by the bid structure. Concluding comments are gathered in Section 5.

\footnotetext{
${ }^{10}$ Incumbents may possibly "hide" their identity behind a new name if they are legally not allowed to acquire a new license .

${ }^{11}$ The effect of entry on profits are well-documented. Consider the following quotations: "The arrival of four new PCS carriers in some US cities - breaking up the old cellular duopolies that had existed before - has driven down prices, one of the factors behind the growth in new subscribers" (Financial Times, Friday February 5, 1999)

"Israeli Cable firms complained that the approval of direct broadcast satellite television (DBS) was an unfair infringement on their monopoly. The High Court of Justice dismissed the petition, but ordered the government to negotiate some kind of compensation. Under a recent deal, the cable companies will receive permission to embark in a new field of operation - domestic communications in exchange for giving up their exclusive rights to most television channels and agreeing to share programming with DBS operators." (Haaretz, Tuesday, February 9, 1999).

${ }^{12}$ As mentioned above, the positive correlation between competitiveness and consumers' surplus can be made specific by adding extra structure about aggregate demand. But that extra structure is rarely accessible to the regulatory agency at the time of the auction, and the public debate often revolves around the degree of competitiveness that the auction induces.
} 
Our main insights are as follows. Suppose that incumbents currently earn large profits, that old and new licenses are close substitutes, and that the addition of one licensed entrant causes a significant drop in per-firm profit in the industry ${ }^{13}$. Then bidding among incumbents displays "war of attrition" features: since entry preemption has a public good aspect, incumbents are willing to buy new (even "worthless") licenses or capacity in order to avoid entry, while, at the same time, preferring that the cost of preemption is born by others.

If only one license is auctioned, the war of attrition leads to entry with positive probability. In this case we also show that the incentives for explicit collusion are highest when the expected benefit for entrants is approximately equal to the difference between the incumbents' post- and pre-entry profits.

The war of attrition between incumbents can be alleviated if several licenses are auctioned, resulting in less entry. The point is that, with more licenses, the cost of preemption can be more easily shared among incumbents (even though the cost is higher). If the number of licenses equates the number of incumbents, each of them can purchase one license. This completely preempts entry, and the cost is equally shared among incumbents. Recall that this was the outcome of the Dutch 3G auction.

The above insight suggests that auctioning the maximum possible number of licenses need not induce a higher degree of competitiveness. Restricting supply is a way to combat tacit collusion and to induce more entry. Another way to combat tacit collusion is to use sequential auctions with some supply uncertainty about the number of future licenses ${ }^{14}$. In some cases, this format induces more entry than supply restriction.

If the number of licenses exceeds the number of incumbents, we display plausible conditions under which all incumbents get a license. This result fits the outcome of the German and UK 3G license auctions.

Our analysis points out that the induced entry and revenue obtained in various auction formats crucially depends on the relation between the number of incumbents and the number of auctioned licenses. We also note that competitiveness and revenue may be both positively or negatively correlated, depending on the parameters of the model.

\footnotetext{
${ }^{13}$ Possibly, because prior to entry the incumbent firms managed to achieve some form of collusion.

${ }^{14}$ Although clearly unintended, the Spanish government is using such a procedure. After the first 3G licenses were awarded last year (for free, via a beauty contest), the government now considers to create a new license and sell it through auction.
} 
Finally, we briefly review an auction format proposed by GTE (in the universal service context) in which the winners of the auction are those bidders who have submitted bids in a given range below the highest bid (say $15 \%$ within the highest bid). Thus, the number of new licenses is endogenously determined by the bid structure. Such auction formats may prevent the incumbents from achieving a totally collusive agreement, and we suggest that they can perform better than a systematic supply restriction of new licenses. On the other hand, the endogenization of the number of licenses must be carefully done in order to avoid designs such as the German one discussed above.

\subsection{Related literature}

The analysis performed here is related to models considered in the literature on patent licensing, pioneered in Arrow (1962) (see the survey of Kamien, 1992). Gilbert and Newbery (1982) use an auction model to study the interaction between a monopolist incumbent and a potential entrant competing for an innovation. Their main result is the persistence of the monopolist which takes into account the potential negative externality and uses preemptive patenting. Krishna (1993, 1999) and Gale and Stegeman (2000) study sequential auctions of inputs and show that monopoly may not persist in that context. Rodriguez (1997) studies sequential license auctions in a model with incumbents and entrants. He imposes conditions on the reduced-form downstream profit functions which directly induce sure entry at each auction (unless the initial market structure is monopolistic, in which case the Gilbert-Newbery result applies). McAfee (1998) studies capacity auctions in oligopolies where some firms are capacity constrained, and points out the resulting externalities. He shows that unconstrained firms may win the auction in some cases.

Kamien and Tauman (1986), Kamien, Tauman and Oren (1992) and Katz and Shapiro $(1985,1986)$ study patent licensing in oligopolistic downstream industries and specifically point out the presence of allocative externalities among firms. These authors assume that all firms are ex-ante symmetric ${ }^{15}$ - this is the key difference between theirs and our work. Jehiel and Moldovanu (1996a) allow for ex-ante asymmetries among the downstream competing firms and focus on the incentives to participate in an auction for a cost-reducing innovation protected

\footnotetext{
${ }^{15}$ This assumption is common in practically the entire literature on vertical relations - see Segal, 1999 for a theoretically unifying approach. An exception is Rockett, 1990 who studies the externalities caused by asymmetric licensees on the licensor (but not on each other).
} 
by a patent. Jehiel and Moldovanu (1997) and Jehiel et. al. (1996b, 1999) look at models where one object is auctioned and where agents possess private information about imposed or incurred externalities. The focus in the last two papers is on mechanism design and on revenue maximizing sales procedures ${ }^{16}$. Jehiel and Moldovanu (2000) provides a detailed study and critique of the special German design for the $3 \mathrm{G}$ license auction.

The free-riding phenomenon among incumbents is connected to the positive externality identified in the literature on mergers (see Perry and Porter 1985, McAfee and Williams 1988, Farrell and Shapiro 1990). However, this literature does not discuss the resulting war of attrition. For an analysis of such a war of attrition in a bargaining context, see Jehiel and Moldovanu (1995a,b). The possibility of collusive-like outcomes in auctions for several objects has been studied by Wilson (1979) and Anton and Yao (1992), and more recently by Ausubel and Schwarz (1999), Brusco and Lopomo (1999), and Klemperer (2000). Papers that focus on informational asymmetries in market design are Auriol and Laffont (1992), Dana and Spier (1994), McGuire and Riordan (1995), and Milgrom (1996). Jehiel and Moldovanu (1998) offer a general (and abstract) perspective on efficient multi-object auctions with allocational and informational externalities.

\section{The Model}

We consider an industry with $n$ incumbents. New firms can enter the market by acquiring licenses from a regulatory agency. We assume that there are $m$ potential entrants.

The regulatory agency organizes an auction for new licenses. New licenses may differ in specification from the licenses owned by incumbents. Our model allows for various forms of substitutability/complementarity between old and new licenses.

In each feasible configuration, we assume that firms' profits solely depend on the number of active firms after the auction. That is, suppose $k$ licenses are auctioned and suppose $s \leq k$ entrants acquire a license (and thus $k-s$ incumbents acquire a new license). Then the number of active firms after the auction is $n+s$, and all payoffs depend on $n+s$ as follows:

1. An unsuccessful entrant receives a payoff of zero.

\footnotetext{
${ }^{16} \mathrm{~A}$ major problem with the revenue-maximizing procedures in the presence of externalities is that the seller needs an unrealistically strong commitment power in order to implement the rather sophisticated optimal schemes.
} 
2. A successful entrant receives a payoff of $w_{e}(n+s)$.

3. An unsuccessful incumbent receives a payoff of $\pi(n+s)$.

4. A successful incumbent receives a payoff of $w_{i}(n+s)$.

We assume that the profit functions $\pi, w_{e}, w_{i}$ are decreasing in their arguments. We also assume that $\forall t, w_{i}(t) \geq \pi(t)$, and $w_{e}(t) \geq 0$. We denote $v(t) \equiv w_{i}(t)-\pi(t)$. All profit functions are assumed to be common knowledge among bidders. The status quo corresponds to the case $k=0$.

It is convenient to denote $d(n)=d=\frac{\pi(n)-\pi(n+1)}{w_{e}(n+1)}$ and $g(n)=g=\frac{v(n)}{w_{e}(n+1)}$. The parameter $d$ will be called the market structure parameter, whereas $g$ will be called the direct benefit parameter.

The above setup is sufficiently general to cover many applications of interest. For example, if new and old licenses are perfect substitutes, then $\pi \equiv w_{e} \equiv w_{i}$ and $v \equiv 0$. If they are imperfect substitutes and a new license is more valuable to incumbents than an old one, then $v>0$. If entrants have to incur a fixed cost $c$ to catch up the incumbents' advantage, but old and new licenses are otherwise perfect substitutes, then $\pi \equiv w_{i}$ and $w_{e} \equiv \pi-c$, and so on ${ }^{17} \ldots$

In some applications we extend the model and allow the payoff functions $w_{e}$ and $v$ to depend also on the number of new licenses $k$ (besides the dependence on the number of active firms). These functions will be then denoted by $w_{e}^{k}(n+s)$ and $v^{k}(n+s)$, respectively. Such an extension is needed if the profit induced by the new license has some component which depends on the specific market structure associated with the new license market ${ }^{18}$.

Incumbents on the one hand, and entrants on the other are assumed to be symmetric. This is to highlight the effect of the asymmetry between incumbents and entrants (rather than the asymmetry within a given group). Throughout the paper, we focus on equilibria where symmetric bidders use symmetric strategies, and where bidders do not use (weakly) dominated strategies. ${ }^{19}$ To ensure the existence of equilibria in our complete information models we need tie-breaking assumptions: these are tailored to the specific auctions (an equivalent alternative

\footnotetext{
${ }^{17}$ The model also covers the case (which is less interesting from the viewpoint of this paper) in which the activities of the two licenses are completely independent. This corresponds to $\pi$ being constant.

${ }^{18}$ For example, consider the markets for $3 \mathrm{G}$ and $2 \mathrm{G}$ mobile telephony.

${ }^{19}$ Equilibrium considerations would automatically yield the restriction to (weakly) undominated strategies if some private information perturbation, say on valuations, were introduced.
} 
is to introduce a smallest money unit). Basically, the tie-breaking rules say that incumbents are treated symmetrically, and that high bidding entrants cannot get licenses as long as there are unserved incumbents willing to make bids at least as high.

\section{Auctions for one license}

In this Section we assume that there is one license for sale, i.e. $k=1$. The license is sold through a Vickrey or sealed-bid second price auction ${ }^{20}$. All bidders simultaneously submit bids, which are non-negative real numbers. The bidder with highest bid gets the license and pays the second highest bid for it.

The main thing to note is the fundamental difference between incumbents and potential entrants with respect to the nature of their willingness to pay: If an entrant acquires the license at a price $p \leq w_{e}(n+1)$, then it expects an increase in payoff from zero to $w_{e}(n+1)-p$, whereas the incumbents experience a decrease of payoff from $\pi(n)$ to $\pi(n+1)$. If an incumbent acquires the license at a price $p$, then he experiences a change in payoff from $\pi(n)$ to $\pi(n)+v(n)-p$, and all other incumbents receive $\pi(n)$. Hence, an entrant is prepared to pay up to $w_{e}(n+1)$ for a license, and an incumbent is prepared to pay up to $\pi(n)-\pi(n+1)+v(n)$ or $v(n)$, depending on whether he expects an entrant or another incumbent to acquire the license instead. The outcome of the auction will vary, depending on the relation between $w_{e}(n+1), \pi(n)-\pi(n+1)+v(n)$, and $v(n)$. There are several cases of interest:

1. Assume that $d+g<1$ (i.e., $\left.\pi(n)-\pi(n+1)+v(n)<w_{e}(n+1)\right)$ In this case, an entrant's expected payoff $w_{e}(n+1)$ is higher than the maximum willingness to pay of an incumbent ${ }^{21} \pi(n)-\pi(n+1)+v(n)$. Entry occurs for sure, and, assuming that there are at least two potential entrants, the successful entrant has to pay $w_{e}(n+1)$, which is the revenue of the auction.

2. Assume that $1<g$ (i.e., $\left.w_{e}(n+1)<v(n)\right)$. In this case the direct benefit of an incumbent is by itself higher than the expected payoff an entrant. Entry is not possible, and the preemption motive becomes irrelevant. At the auction the incumbents compete for the license, the expected payoff of incumbents is $\pi(n)$ (i.e., the premium of the winning incumbent is dissipated in competition), and the revenue is given by $v(n)$.

\footnotetext{
${ }^{20}$ The English ascending price auction yields here the same results.

${ }^{21}$ This willingness to pay is the sum of the direct benefit and the benefit of preemption.
} 
3. Assume that $g<1<d+g$. In this case the entrants' willingness to pay $w_{e}(n+1)$ is less than the incumbents' willingness to pay for preemptive motives, i.e. $\pi(n)-\pi(n+1)+v(n)$, but more than the incumbents' willingness to pay for direct motives, i.e. $v(n)$. If there is only one incumbent, then his willingness to pay is unambiguously defined by $\pi(n)-\pi(n+1)+v(n)$, and the incumbent acquires the license with probability one ${ }^{22}$. An interesting phenomenon occurs when there are $n>1$ incumbents. A bidding "war of attrition" takes place among the incumbents, since their bids must balance two conflicting interests: on the one side they wish to pre-empt entry, but on the other side they wish to let some other incumbent pay the price of preemption.

In order to ensure equilibrium existence we use the following tie-breaking rule: an entrant with a highest bid cannot win the license if there exists at least an incumbent that has made the same highest $\mathrm{bid}^{23}$. Moreover, if $s$ incumbents tie at the highest bid, then each wins the license with probability $\frac{1}{s}$.

Proposition 3.1. Assume that $k=1$, and that there are $n>1$ incumbents. Assume also that $g<1<d+g$. Let $\delta=\frac{d}{1-g}$. The payoffs of entrants and incumbents are uniquely defined in a symmetric equilibrium. Each entrant bids $w_{e}(n+1)$. Each incumbent bids $w_{e}(n+1)$ with probability $q(\delta, n)$, and bids 0 (or below $w_{e}(n+1)$ ) with probability $1-q(\delta, n)$, where $q=q(\delta, n)$ is implicitly defined by

$$
\delta=\frac{1-q}{n q} \cdot\left[(1-q)^{-n}-1\right] .
$$

A potential entrant gets the license with probability $x(\delta, n)=(1-q(\delta, n))^{n}$, and has a zero expected profit. An incumbent's expected profit is given by:

$$
v_{\text {inc }}(\delta, n)=\left[1-(1-q(\delta, n))^{n-1}\right] \pi(n)+(1-q(\delta, n))^{n-1} \pi(n+1) .
$$

Proof. See Appendix.

The equilibrium entry probability $x(\delta, n)$ is entirely determined by the number $n$ of incumbents and the parameter $\delta=\frac{d}{1-g}$, which aggregates the market structure and the direct benefit parameters. We have:

\footnotetext{
${ }^{22}$ This is the standard case of monopoly persistence (see Gilbert and Newbery, 1982).

${ }^{23}$ The obtained equilibrium corresponds to the limit as $\varepsilon \rightarrow 0$ of the equilibria obtained when (1) all bidders with highest bid have the same probability of getting the license and (2) bids can only take values of $\varepsilon, 2 \varepsilon, 3 \varepsilon, \ldots$
} 
Proposition 3.2. Assume that $g<1<d+g$. In the one-license auction, the probability of entry $x(\delta, n)$ is a decreasing function of $\delta$ and an increasing function of $n$.

Proof. See Appendix.

It is relatively intuitive that the probability of entry decreases in $d$ and in $g$ (and thus in $\delta$ ): for larger $d$, the incumbents are more willing to avoid entry, and for larger $g$, the net cost of acquiring a license for an incumbent is smaller. It is less straightforward to see that this probability decreases in $n$ : on the one hand, the free riding problem among incumbents becomes more severe as $n$ increases, which induces a higher probability of entry; on the other hand, for a given strategy of incumbents, the probability that all $n$ incumbents bid zero (and hence that an entrant wins the license) is decreasing in $n$. Proposition 3.2 shows that the first effect is dominant.

The next Proposition establishes the overall behavior of the equilibrium entry probability as a function of the number of incumbents $n$.

Proposition 3.3. Assume that the function $\delta(n)=\frac{d(n)}{1-g(n)}$ decreases in $n$. Then the probability of entry $x(\delta(n), n)$ is a non-decreasing function of $n$.

Proof. We need to show $x(\delta(n+1), n+1) \geq x(\delta(n), n)$. There are several cases to consider:

1. If $\delta(n) \leq 1$ then $\delta(n+1) \leq 1$. In this case there is sure entry (whether there are $n$ or $n+1$ incumbents) and $x(\delta(n+1), n+1)=x(\delta(n), n)$.

2. If $\delta(n+1) \leq 1<\delta(n)$ then there is sure entry with $n+1$ incumbents, but not with $n$ incumbents, so that $x(\delta(n+1), n+1)=1 \geq x(\delta(n), n)$.

3. If $\delta(n) \geq \delta(n+1) \geq 1$, we obtain by Proposition 3.2 :

$$
x(\delta(n+1), n+1) \geq x(\delta(n), n+1) \geq x(\delta(n), n) .
$$

Whether or not the function $\frac{d(n)}{1-g(n)}$ is decreasing depends on the specific IO context. For example, in the case of perfect substitutability where $g=0$ and $w_{e}=\pi$, the monotonicity of $\delta(n)$ reduces to the requirement that $\frac{\pi(n)-\pi(n+1)}{\pi(n+1)}$ is decreasing, which is satisfied in many oligopoly models. $n=3$.

We conclude this subsection by presenting explicit formulae for $n=2$ and 
Example 3.4. The solution of equation (3.1) for $n=2$ is $q=\frac{2 \delta-2}{2 \delta-1}$, and the probability of entry is given by $(1-q)^{2}=\frac{1}{(2 \delta-1)^{2}}$. The solution for $n=3$ is $q=\frac{1}{2(3 \delta-1)}(6 \delta-3-\sqrt{(12 \delta-3)})$ and the probability of entry is given by $(1-$ $q)^{3}=\frac{1}{8} \frac{(1+\sqrt{(12 \delta-3)})^{3}}{(3 \delta-1)^{3}}$. The probabilities of entry as a function of $\delta$ are depicted in the following figure.

\section{Insert Figure 1 here}

\subsection{Explicit collusion among incumbents}

In this subsection we consider the possibility of explicit collusion ${ }^{24}$ among incumbents. We wish to compare the highest collusive payoff incumbents could achieve (using any kind of mechanism) to the payoff they obtain in the non-collusive bidding analyzed above ${ }^{25}$.

Let $\Delta^{C}$ be the per-firm profit of incumbents under perfect collusion and let $\Delta^{N C}$ be the profit of incumbent firms in the above symmetric equilibrium outcome. The entrants' willingness to pay is invariably $w_{e}(n+1)$. Note that when incumbents collude, the price paid for the license is always $w_{e}(n+1)$, since the absence of competition between incumbents drives down the price to entrants' willingness to pay of entrants.

We wish to compare the difference $\Delta^{C}-\Delta^{N C}$ to $w_{e}(n+1)$, and we denote

$$
\Delta=\frac{\Delta^{C}-\Delta^{N C}}{w_{e}(n+1)}
$$

The higher this ratio, the higher the incumbents' incentive to collude. There are several cases of interest:

1. If $g=\frac{v(n)}{w_{e}(n+1)}>1$, then $\Delta^{N C}=\pi(n)$, and $\Delta^{C}=\pi(n)+\frac{v(n)-w_{e}(n+1)}{n}$. Thus, $\Delta=\frac{g-1}{n}$. In this case, collusion among incumbents takes the standard form of avoiding wasteful competition.

\footnotetext{
${ }^{24}$ By explicit collusion, we mean a situation where incumbents can fully agree on their bidding behavior at the auction, and can make any kind of transfers between themselves, possibly outside the auction.

${ }^{25}$ Caillaud and Jehiel (1998) study collusion in simpler IO setup, but with asymmetric information among bidders. They show how market structure considerations may complicate the information sharing among colluding bidders.
} 
2. If $g<1$, the main incumbents' motive for acquiring the license is to preempt entry. The cost of preemption is determined by the entrants' willingness to pay, i.e. $w_{e}(n+1)$. Preemption is thus desirable for the incumbents' ring whenever $n \pi(n)+v(n)-w_{e}(n+1)>n \pi(n+1)$, that is, whenever $\frac{d}{1-g}>\frac{1}{n}$, in which case $\Delta^{C}=\pi(n)+\frac{v(n)-w_{e}(n+1)}{n}$. If $\frac{d}{1-g} \leq \frac{1}{n}$, entry occurs for sure and we have $\Delta^{C}=\pi(n+1)$. This yields for $g<1$ :

$$
\Delta= \begin{cases}0 & \text { if } \frac{d}{1-g} \leq \frac{1}{n} \\ d-\frac{1-g}{n} & \text { if } \frac{1}{n}<\frac{d}{1-g}<1 \\ \left(d+\frac{g}{n}\right)(1-q)^{n-1}-\frac{1}{n} & \text { if } \frac{d}{1-g} \geq 1\end{cases}
$$

For $\frac{d}{1-g}$ small enough, collusion is not beneficial for the incumbents: in the non-cooperative equilibrium, an entrant gets the license and there is no point to avoid that entry even when taking into account the profit loss incurred by every incumbent. For $\frac{1}{n}<\frac{d}{1-g}<1$, there is some benefit of collusion: In the non-cooperative outcome there is sure entry, because the cost to an individual incumbent does not justify preemption; however, taking into account the loss of every incumbent it is worth preempting entry. For $\frac{d}{1-g}>1$ there is a clear benefit of collusion, that of avoiding the risk that an entrant gets the license with some positive probability.

Observe that $\Delta=0$ for $\frac{d}{1-g} \leq \frac{1}{n}$ and that $\Delta$ tends to 0 as $\delta=\frac{d}{1-g}$ tends to infinity ${ }^{26}$. Collusion is not very beneficial when $\frac{d}{1-g}$ is very large because, despite the war of attrition, an entrant very rarely gets the license in the non-cooperative equilibrium. This suggests that we should expect more collusion among incumbents when the market structure parameter is neither too low nor too large.

Example 3.5. For illustrative purposes, consider the explicit formulae for $n=$ 2,3 and $g=0$ :

$$
\Delta= \begin{cases}0 & \text { if } d \leq \frac{1}{2} \\ d-\frac{1}{2} & \text { if } \frac{1}{2}<d<1 \quad \text { for } n=2 \\ \frac{d}{2 d-1}-\frac{1}{2} & \text { if } d \geq 1\end{cases}
$$

and

\footnotetext{
${ }^{26}$ To see this, recall expression 3.1 and note that $q$ tends to 1 when $\delta$ tends to infinity. Then, plug the expression of $\delta$ to show that $\delta(1-q)^{n-1}$ tends to $\frac{1}{n}$.
} 


$$
\Delta=\left\{\begin{array}{ll}
0 & \text { if } d \leq \frac{1}{3} \\
d-\frac{1}{3} & \text { if } \frac{1}{3}<d<1 \\
\frac{d(1+\sqrt{(12 d-3)})^{2}}{4(3 d-1)^{2}}-\frac{1}{3} & \text { if } d \geq 1
\end{array} \text { for } n=3\right.
$$

The following figure plots the relative benefit of collusion as a function of $d$ and reveals that this benefit is maximal at $d=1$.

\section{Insert Figure 2 here.}

\section{Multi-License Auctions}

In this Section we analyze the effect of auctioning several licenses. We consider the Vickrey auction (which extends here the sealed-bid second-price auction used for $k=1)$ : each bidder $i$ submits a bid $b_{i}$; the bidders with the $k$ highest bids get a license each and pay the $(k+1)$ highest bid. That is, rearranging the bids in increasing order, $b_{i(1)} \geq \cdots \geq b_{i(k)} \geq b_{i(k+1)} \geq \cdots$, every bidder $i(1), \cdots, i(k)$ gets a license and pays $b_{i(k+1)}{ }^{27}$. The simultaneous ascending price version (where the price gradually increases until there are $k$ remaining bidders who each obtains a license and pays the current price) yields here the same results ${ }^{28}$.

\subsection{When all incumbents get licensed}

In the British UMTS auction there were 5 licenses, one more than the number of GSM incumbents. All 4 incumbents obtained a new license. In light of our model this is not surprising since, besides expecting a higher direct benefit (due to lower infrastructure costs), incumbents are also driven by preemption motives. The following Proposition makes this observation precise.

Proposition 4.1. Assume that $k>n$ and that $\pi(k)-\pi(k+1)+v(k)>w_{e}(k) . A$ symmetric equilibrium of the $k$-license auction is as follows: entrants bid $w_{e}(k)$, and incumbents bid above that (say $\pi(k)-\pi(k+1)+v(k)$ ). All incumbents get a license, and $k-n$ entrants get a license. All licenses are sold, and the revenue is given by $k w_{e}(k)$.

\footnotetext{
${ }^{27}$ We describe below the appropriate tie-breaking rule guaranteeing the existence of equilibrium.

${ }^{28}$ The same applies here for the ascending format used by the FCC (see Milgrom, 2000).
} 
Proof. If the above strategy profile is played, entrants get a payoff of zero, and incumbents get a payoff of $w_{i}(k)-w_{e}(k)=v(k)+\pi(k)-w_{e}(k)$. The above strategies form an equilibrium because: 1) Given that all other firms bid at least $w_{e}(k)$ and given that all licenses are sold, incumbent $i$ has no incentive to bid below that since this would give him a payoff of $\left.\pi(k+1)<v(k)+\pi(k)-w_{e}(k) ; 2\right)$ Given that an entrant expects that $n$ out of $k$ licenses will be sold to incumbents, the value of a license to an entrant is $w_{e}(k)$.

Two cases must be qualitatively distinguished in the interpretation of Proposition 4.1. If $v(k)>w_{e}(k)$, incumbents intrinsically value the license more than entrants, and therefore it is legitimate that they are served first. But they continue to be licensed with probability 1 even if $v(k)<w_{e}(k)$, as long as $\pi(k)-\pi(k+1)+v(k)>w_{e}(k)$. This corresponds to the preemptive motive.

Suppose now that the number of auctioned licenses $k$ coincides with the number of incumbents $n$. This was the Dutch case ( 5 licenses, 5 incumbents) where no entry occured.

Proposition 4.2. Assume that $\pi(n)-\pi(n+1)+v(n)>w_{e}(n+1)$. The following strategies define an equilibrium of the Vickrey auction with $k=n$ licenses: Incumbents bid above $w_{e}(n+1)$, say $\pi(n)-\pi(n+1)+v(n)$. Entrants bid $w_{e}(n+1)$. The incumbents acquire one license each at price $w_{e}(n+1)$. There is no entry and total revenue is $n w_{e}(n+1)$.

Proof. The above strategies form an equilibrium because: 1) Given that incumbent $i$ bids above $w_{e}(n+1)$, incumbent $i^{\prime}$ has no incentive to bid below $w_{e}(n+1)$. Incumbent $i^{\prime}$ would then leave one license to an entrant, and his resulting payoff would be $\pi(n+1)<\pi(n)+v(n)-w_{e}(n+1)$; 2) Given that an entrant expects that all other licenses go to incumbents, the value of a license to an entrant is $w_{e}(n+1)$.

As in the case $k>n$, two scenarios must be qualitatively distinguished in the above Proposition according to how $g(n)$ compares to 1 . If $g(n)>1$, the direct benefit for the new license is superior for incumbents than for entrants, and therefore it is legitimate that incumbents acquire a license.

If $g(n)<1$, entrants intrinsically value the new license more than incumbents do. However, when $d(n)+g(n)>1$, incumbents are willing to acquire one license each, so that no entrant can get in this market. It is interesting to compare this result with the one derived under the same conditions in the one-license auction: there, an entrant had a positive probability of getting a license due to the war of attrition between the incumbents. When $k=n$ licenses are auctioned, there is 
an easy way to share the price of preemption: each incumbent buys one license, and the war of attrition disappears, leading to prefect preemption. Restricting attention to the equilibria displayed in Propositions 3.1 and 4.2, we get:

Corollary 4.3. Suppose that $d(n)+g(n)>1>g(n)$. The expected number of entries when one license is auctioned is higher than the expected number of entries when $k=n$ licenses are auctioned.

Remark: Proposition 4.2 has displayed one equilibrium of the $n$-license Vickrey auction, but sometimes several equilibria exist. To illustrate the point, assume that there are $n=2$ incumbents, and that 2 licenses are sold. If $d(3)+g(3)>1$, the above equilibrium outcome is the unique outcome of symmetric equilibria in undominated strategies. If $d(3)+g(3)<1$, there is another symmetric equilibrium that induces a very different outcome: entrants bid $w_{e}(4)$, and incumbents bid below $w_{e}(4)$. Hence two entrants get new licenses at price $w_{e}(4)$.

The multiplicity in the case $d(3)+g(3)<1<d(2)+g(2)$ is caused, essentially, by a coordination problem among incumbents. If incumbent 1 expects incumbent 2 to make a low bid, the question is whether there will eventually be 3 or 4 active firms in the industry. Since $d(3)+g(3)<1$, incumbent 1 is also not willing to acquire a license. If incumbent 1 expects incumbent 2 to make a high bid, the question is whether there will eventually be 2 or 3 active firms, and incumbent 1 is then willing to acquire a new license (since $d(2)+g(2)>1$ ).

From the point of view of incumbents ${ }^{29}$, the full preemption equilibrium Paretodominates the full entry equilibrium. The risk-dominance analysis is complicated due to the fact that the entrants use different strategies in each equilibrium. A simple case in which this difficulty does not arise is the one where $w_{e}(3)=w_{e}(4)$ and $g(3)=g(4)=0$. Then entrants have a (weakly) dominant strategy: bid $w_{e}(3)=w_{e}(4)$. In a Vickrey auction where incumbents are restricted to make a bid below $w_{e}(3)$ or a bid above $w_{e}(3)$, we can apply the standard definition of risk-dominance (see Harsanyi and Selten, 1988) and we find that the full preemption equilibrium risk-dominates the full entry equilibrium whenever $d(2)>2 .{ }^{30}$ In our discussion we will mostly focus on the Pareto-dominant equilibrium.

\footnotetext{
${ }^{29}$ Entrants get 0 anyway.

${ }^{30}$ In the ascending price version, the risk-dominance criterion is slightly different (giving some more advantage to the fully preemptive equilibrium), but the criteria become identical in the limit where the number $m$ of entrants gets very large.
} 


\subsection{Supply restriction}

Corollary 4.3 shows that an auction for one license may induce more entry than an auction for $n$ licenses when $d(n)+g(n)>1, g(n)<1$ and the functions $v$ and $w_{e}$ do not depend on $k$. If the primary concern is to induce more competitiveness, and at most $n$ licenses can be auctioned, ${ }^{31}$ then restricting the number of auctioned licenses may be desirable. Note that revenue is undoubtedly higher in the $n$-license auction (where it is equal to $n w_{e}(n+1)$ ) than in the one-license auction (where it is equal to $w_{e}(n+1)$ ). Hence the tension between competitiveness and revenue is acute. The rest of this subsection considers several forms of supply restriction, and also considers the case where more than $n$ licenses can be auctioned.

\subsubsection{Optimal deterministic supply restriction}

Given the above general observation, it makes sense to ask what is the optimal number of licenses from the point of view of inducing entry. This turns out to be a difficult question even in the perfect information setting considered here. The main difficulty is that whenever $d(n)+g(n)>1$ and $g(n)<1$, the $k$-license auction with $k<n$ has the structure of a war of attrition with $k$ objects, and it is very hard to compare the probabilities of entries for the various $k, k<n$.

We provide a partial answer to the above question in a setting where the benefit functions $v^{k}$ and $w_{e}^{k}$ depend on the number $k$ of auctioned licenses. We let $d^{k}, g^{k}$ be the corresponding market structure and direct benefit parameters ${ }^{32}$.

Proposition 4.4. Fix $\bar{k}<n$, and assume that $d^{n}(n)+g^{n}(n)>1$ and that $g^{k}(n)<1$ if and only if $k \geq \bar{k}$. Assume also that there are at most $k=n$ licenses. Then the expected number of entries is maximized for $k^{\prime} \in[\bar{k}, n-1]$.

Proof. We have $g^{k}(n)>1$ for $k<\bar{k}$. Thus if $k<\bar{k}$ licenses are auctioned, incumbents acquire all of them, and there is no entry. By Proposition 4.2, there is no entry either if $k=n$ licenses are auctioned. If $\bar{k}$ licenses are auctioned, there is entry with positive probability whether or not $d^{\bar{k}}(n)+g^{\bar{k}}(n)>1$. Hence the maximum must occur for $k^{\prime} \in[\bar{k}, n-1]$.

Remark: It is more likely that $g^{k}(n)$ is a decreasing function of $k$, since benefits associated with the new licenses are probably larger when fewer new licenses are available. The assumption on $g^{k}(n)$ is then plausible.

\footnotetext{
${ }^{31}$ For example. in some cases there are capacity limitations that physically limit the number of possible licenses.

${ }^{32}$ In the next Proposition, we consider the Pareto-efficient symmetric equilibrium.
} 
Proposition 4.4 shows that a transition from $k=n$ to $k<n$ may be beneficial for competitiveness. But what about situations in which more than $n$ licenses can be auctioned? Obviously, if $2 n-1$ or more licenses are auctioned, at least $n-1$ entrants will acquire a license, and there is no way to induce a higher competitiveness by auctioning $k<n$ licenses.

Assume then that at most $k<2 n-1$ licenses can be auctioned. The following Proposition identifies simple circumstances under which, in case $k<n$, more entry is expected than in the cases where $k \in[n, 2 n-2]$.

Proposition 4.5. Assume that for all $k, w_{e}(k)=w_{e}, v(k)=v, \pi(k)-\pi(k+$ $1)=\Delta \pi>0$ and that $\frac{\Delta \pi+v}{w_{e}}=1+\varepsilon>1$. Then, if $\varepsilon$ is small enough, for all $k \in[0,2 n-2]$, the expected number of entries is maximized when $n-1$ licenses are auctioned.

Proof. If $k \geq n$ licenses are auctioned, Propositions 4.1 and 4.2 show that all incumbents get licensed. Hence, the number of entries is 0 (if $k=n$ ) or $k-n$ (if $k>n)$.

If $k<n$ licenses are auctioned, there is a war of attrition phenomenon. Entrants bid $w_{e}$, and incumbents use a mixed strategy ${ }^{33}$ : bid $w_{e}$ with probability $q$, and bid 0 with probability $1-q$. In equilibrium an incumbent has to be indifferent between bidding 0 and bidding $w_{e}$. Bidding $w_{e}$ is effective and hence advantageous relatively to a bid of 0 only if at most $k-1$ other incumbents bid $w_{e}$. The net gain provided by such a bid is $\Delta \pi+v-w_{e}=\varepsilon w_{e}$. If $k$ or more incumbents bid $w_{e}$, such a bid has a cost of at least $\frac{k}{n}\left(w_{e}-v\right)>00^{34}$. As $\varepsilon$ goes to 0 , the probability $q$ must also converge to 0 (so that the indifference condition continues to hold). When $q$ is close to 0 , there are approximately $k$ entries on expectation, hence the number of entries is maximized by setting $k=n-1$.

The intuition for Proposition 4.5 is as follows. Given that $\Delta \pi+v>w_{e}$, Propositions 4.1 and 4.2 guarantee that if $k \geq n$ licenses are auctioned all incumbents get a license. Thus, if $k \geq n$ the number of entries is increasing in $k$. If $k<n$ licenses are auctioned, the condition $\frac{\Delta \pi+v}{w_{e}}=1+\varepsilon$ implies that $v<w_{e}$ for $\varepsilon$ small enough. Thus, we are in the war of attrition regime in which the incumbent's intrinsic value for the new license is lower than that of entrants, but the preemption value is higher. The outcome of this war of attrition depends on the magnitude of $\Delta \pi+v-w_{e}$. When $\Delta \pi+v-w_{e}$ is small, the surplus to be gained by preemption

\footnotetext{
${ }^{33}$ Remember that we restrict attention to incumbent-symmetric equilibria.

${ }^{34}$ Note that this expression does not converge to 0 as $\varepsilon$ gets small.
} 
is small, and therefore incumbents do not bid above $w_{e}$ with a high probability. This results in almost $k$ entries, and Proposition 4.5 follows.

The conditions displayed in Proposition 4.5 are obviously restrictive ${ }^{35}$. However, Proposition 4.5 clearly shows that auctioning less licenses may induce more entry. The main reason is that preemption takes the strategic form of tacit collusion if $k \geq n$ and the form of an war of attrition if $k<n$.

\subsubsection{Random Supply}

Another way to restrict supply is to have a random number of licenses. We illustrate the potential benefit of random supply in an example with two incumbents: one license is auctioned first (through a sealed bid second price auction), and then a second license is auctioned with probability $u^{36}$. The probability $u$ is common knowledge. Note that $u=0$ corresponds to the one-license auction studied in Section 3 and that $u=1$ corresponds to a deterministic sequential two-license auction (which leads here to the same insights as the simultaneous two-license Vickrey auction).

The following example exhibits a setting where the random supply auction induces more entry than both a one-license and a two-license auction.

Example 4.6. Consider the case where old and new licenses are perfect substitutes, i.e. $g \equiv 0, w_{e} \equiv \pi$. Suppose further that $\pi(3)=\pi(4)$ (i.e., $d(3)=0$ ) and let $d(2)=\frac{\pi(2)-\pi(3)}{\pi(3)}<1$. In the Appendix we show that there is a unique symmetric Subgame Perfect Nash equilibrium outcome. The expected number of entries is $N=(1-r(u))^{2}(1+u)$, where

$$
r(u)=\frac{d(2)-1}{d(2)-(1+u) / 2}
$$

Assuming that $d(2) \in\left(1, \frac{3}{2}\right)$, the expected number of entries $N$ is maximal for an interior probability $u^{*}, 0<u^{*}<1$. (See Appendix.) The expected revenue is given by $R=(1+u) \pi(3)$, which is an increasing function of $u$, so that it is maximized at $u=1$.

\footnotetext{
${ }^{35}$ The independence with respect to $k$ is unlikely to be satisfied in most cases.

${ }^{36}$ Consider the following quotation from the UK's Radiocommunications Agency information brochure about UMTS licenses: "It (the Government) will press in the international bodies for more spectrum to be allocated, but the timing of extra spectrum being available is very uncertain...there can be no guarantee that there will be an additional operator licensed in the future."
} 


\section{Insert Figure 3 here}

Increasing $u$ has two effects on the entry probability: on the one hand, if an entrant acquires the first license, it increases the probability that a second entrant gets a license $^{37}$ (direct effect); on the other hand, it reduces the intensity of the war of attrition on the first license (since $r(u)$ is an increasing function of $u$ ), which implies that the probability that an entrant gets the first license is a decreasing function of $u$. The optimal probability $u$ has to balance these two effects.

\subsection{Endogenous license supply}

In all auction formats analyzed above, the number of licenses did not depend on bidders' behavior at the auction. We now consider an auction format in which the number of licenses is endogenously determined by the bid structure ${ }^{38}$. Specifically, consider the following auction format (inspired by a proposal submitted by GTE). All bidders simultaneously submit bids. Let $b^{\max }$ be the highest bid. All bidders $i$ who have submitted a bid $b_{i}$ in the interval $\left[(1-h) b^{\max }, b^{\max }\right]$ get a license. The number of winning bidders is thus endogenously determined. The scalar $h \in[0,1]$ is set exogenously, and is part of the description of the auction format. Suppose there are $k$ winners. Then each winning bidder must pay a price equal to the $(k+1)$-highest bid, that is, $b^{(k+1)}$.

In the following Proposition, we assume that $w_{e}$ is a constant, i.e., independent of the number of active firms. We also denote $g=\frac{v(n)}{w_{e}}, d_{m}=\frac{\pi(n)-\pi(n+m)}{w_{e}}$, and $\delta_{m}=\frac{d_{m}}{1-g}$.

Proposition 4.7. Assume that there are $n>1$ incumbents and $m \geq 1$ entrants. Assume that $g<1$ and $d_{m}+g<1$. The following bidding strategies constitute a symmetric Nash equilibrium in undominated strategies ${ }^{39}$ : entrants bid $w_{e}$; each incumbent bids $\bar{b}>\frac{w_{e}}{1-h}$ with probability $q^{G T E}$, and bids 0 with probability $1-q^{G T E}$, where

$$
q^{G T E}=1-\left(\delta_{m}\right)^{\frac{1}{1-n}}
$$

\footnotetext{
${ }^{37}$ One could argue that there is no competitive value of having 4 rather than 3 active firms (since $\pi(3)=\pi(4))$. However, a similar insight holds if $\pi(3)>\pi(4)$ as long as $d(3)=\frac{\pi(3)-\pi(4)}{\pi(4)}<$ 1 . In such a case there is a clear positive competitive effect of having 4 active firms.

${ }^{38}$ Recall that this feature was also part of the German design for the UMTS license auctions.

${ }^{39}$ In the special case where $\pi(n+1)=\cdots=\pi(n+m)$, this is the only symmetric equilibrium in undominated strategies.
} 
Proof. See Appendix.

Remark 1: Despite the fact that several licenses may be sold in equilibrium, the incumbents do not achieve a highly collusive agreement. The equilibrium bidding strategies still reflect the war of attrition among incumbents, and this auction format induces more entry than the $n$-license Vickrey auction analyzed in Proposition 4.2. It is also interesting to compare the entry induced by this auction format with the entry induced when less than $n$ licenses are auctioned. For illustrative purpose, we compare with the entry induced by the one-license auction.

There are two effects which go in opposite direction. One the one hand, the endogenous format exacerbates the market structure parameter and therefore it may induce a lower entry probability . This comes form the observation that, for $m>1, d_{m}$ is likely to be larger than $d=d_{1}$. On the other hand, assuming that $d_{m}$ and $d_{1}$ are close to each other, the nature of the respective wars of attrition is such that the probability of entry is larger in the GTE auction. The point is that the cost of bidding high is greater in the GTE auction than it is in the one-license auction: In the GTE auction, when you bid high, you have to buy the license whereas in the one-license auction, sometimes you do not need to buy it if other incumbents have made a high bid as well. This in turn results in a lower probability that incumbents bid high in the GTE auction than in the one-license auction, and leads therefore to a larger entry probability.

Remark 2: In order to avoid the collusive equilibrium, it is important to keep $h$ constant (i.e., independent of the number of winning bidders). If the auction format were such that, say, $h$ was itself a decreasing function of the number of winning bidders, then tacit collusion could again be achieved ${ }^{40}$.

To conclude this subsection, we note that the endogenous license auction may be suitable to combat tacit collusion among incumbents, and that it may sometimes perform better than an auction with supply restriction ${ }^{41}$.

\footnotetext{
${ }^{40} \mathrm{By}$ adjusting the bids, the incumbents could ensure that if one incumbent makes a low bid, an entrant gets a license with probability 1 .

${ }^{41}$ In the absence of asymmetries between incumbents and entrants, it is unclear whether this type of auction is an adequate tool to select efficient market structure. If all bidders are symmetric, but there are still market structure considerations because the more licensees the lower the profit, then this type of auction may restrict the number of licenses precisely to a point where one additional license would cause the profit to drop a lot (and this may sometimes be a signal that this additional license would be very valuable to the consumers).
} 


\section{Concluding Comments}

We have analyzed the auction of new licenses in an oligopolistic industry. The focus was on the role of market structure considerations in determining the auction's outcome (in particular the number of licensed firms, and the revenue obtained at the auction). An important observation is that the auction format determines the incumbents' possibilities to preempt new entry in the market. In this context, the relation between the number of new licenses and the number of incumbents plays a major role. Finally, we have compared several theoretical results to the results of several recent auctions of licenses in the telecommunication industry.

Most of the auction-theoretic literature focuses on informational problems. In order to conduct a serious discussion about the merits of various auction designs in the context of recent privatization and licensing processes it is necessary to augment those "classical" models by incorporating market structure elements.

\section{Appendix}

Proof of Proposition 3.1: Bidding $w_{e}(n+1)$ is a dominant strategy for entrants, and we now focus on incumbents. For the suggested strategy to be optimal, it must be the case that each incumbent is indifferent between bidding zero and bidding $\pi(n+1)$.

Bidding zero yields an expected payoff of

$$
\begin{gathered}
(1-q)^{n-1} \cdot \pi(n+1)+\left[1-(1-q)^{n-1}\right] \cdot \pi(n)= \\
\pi(n)-(1-q)^{n-1} \cdot[\pi(n)-\pi(n+1)] .
\end{gathered}
$$

Bidding $w_{e}(n+1)$ yields an expected payoff of

$$
\begin{gathered}
\sum_{j=0}^{n-1}\left(\begin{array}{c}
n-1 \\
j
\end{array}\right) \cdot(1-q)^{n-1-j} \cdot q^{j}\left[\pi(n)-\frac{w_{e}(n+1)-v(n)}{j+1}\right]= \\
\pi(n)-\left[w_{e}(n+1)-v(n)\right] \cdot\left[\sum_{j=0}^{n-1}\left(\begin{array}{c}
n-1 \\
j
\end{array}\right) \cdot(1-q)^{n-1-j} \cdot q^{j} \cdot \frac{1}{j+1}\right] .
\end{gathered}
$$

Equating the expected payoffs from the two bids yields the following:

$$
\frac{\pi(n)-\pi(n+1)}{w_{e}(n+1)-v}=\sum_{j=0}^{n-1}\left(\begin{array}{c}
n-1 \\
j
\end{array}\right) \cdot\left(\frac{q}{1-q}\right)^{j} \cdot \frac{1}{j+1}
$$


Noting that $\sum_{j=0}^{n-1}\left(\begin{array}{c}n-1 \\ j\end{array}\right) \cdot\left(\frac{q}{1-q}\right)^{j} \cdot \frac{1}{j+1}=\frac{\left(1+\frac{q}{1-q}\right)^{n}-1}{n\left(\frac{q}{1-q}\right)}$ we $^{42}$ finally obtain:

$$
\frac{d}{1-g}=\frac{1-q}{n q}\left[(1-q)^{-n}-1\right]
$$

Let $G(q)=\frac{1-q}{n q}\left((1-q)^{-n}-1\right)$. Then $\lim _{q \rightarrow 0} G(q)=1$ and $\lim _{q \rightarrow 1} G(q)=\infty$. Moreover, $G^{\prime}(q)>0$ for $q \in[0,1]$. Since by assumption $\frac{d}{1-g} \geq 1$, we obtain that equation 6.2 has always a unique solution $q^{*} \in[0,1]$. An entrant gets the license only when all incumbents bid 0 , hence the probability of entry is $\left(1-q^{*}\right)^{n}$

Proof of Proposition 3.2: The equilibrium probability of entry $x(\delta, n)$ is implicitly defined by

$$
\delta=\frac{x^{\frac{1}{n}}}{n\left(1-x^{\frac{1}{n}}\right)} \frac{1-x}{x} .
$$

Let $w(x, n)=\frac{x^{\frac{1}{n}}}{n\left(1-x^{\frac{1}{n}}\right)} \frac{1-x}{x}$. We will show that $\frac{\partial w}{\partial x}(x, n)<0$ and $\frac{\partial w}{\partial n}(x, n)>0$ so that, by the implicit function theorem, $\frac{\partial x}{\partial n}=-\frac{\partial w / \partial n}{\partial w / \partial x}>0$ and $\frac{\partial x}{\partial \delta}=\frac{1}{\partial w / \partial x}<0$ as desired.

(i) $\frac{\partial w}{\partial n}>0$ is equivalent to

$$
\frac{\partial}{\partial m}\left[\frac{m x^{m}}{1-x^{m}}\right]<0
$$

which is equivalent to

$$
\left[1-x^{m}+\ln \left(x^{m}\right)\right] \frac{x^{m}}{\left(1-x^{m}\right)^{2}}<0 .
$$

Since $1-z+\ln z<0$ for $z \in(0,1)$, we obtain $\frac{\partial w}{\partial n}(x, n)>0$.

(ii) $\frac{\partial w}{\partial x}(x, n)<0$ is equivalent (for $\left.y \in(0,1)\right)$ to

$$
\frac{\partial}{\partial y} \ln \left(\frac{y}{1-y} \cdot \frac{1-y^{n}}{y^{n}}\right)<0
$$

which is equivalent to

$$
-n(1-y)+1-y^{n}<0 .
$$

This condition is easily checked ${ }^{43}$ for $y \in(0,1)$. Hence, $\frac{\partial w}{\partial x}(x, n)<0$.

\footnotetext{
${ }^{42}$ To see this integrate (w.r.t. $z$ ) the following identity: $\sum_{j=0}^{n-1}\left(\begin{array}{c}n-1 \\ j\end{array}\right) \cdot z^{j}=(1+z)^{n-1}$.

${ }^{43}$ The function $-n(1-y)+1-y^{n}$ is equal to zero at $y=1$. Its derivative is positive for $y<1$.
} 
Example 4.6: It remains to analyze the incumbents' equilibrium strategies. Consider the second auction. If the first license has been acquired by an entrant bidder, incumbent bidders bid below $\pi(3)$ and an entrant gets the second license at price $\pi(3)$ (because $d(3)=0<1$ ). If the first license has been acquired by incumbent 1 , then incumbent 2 bids above $\pi(3)$ (say $\pi(2)-\pi(3)$ ) and he gets the second license at price $\pi(3)$ (because $d(2)>1$ ).

Consider now the first auction. As in Section 3, the symmetric equilibrium is in mixed strategies. Each incumbent bidder bids $\pi(3)$ with probability $r$ and 0 with probability $1-r$. The probability $r$ is computed so that an incumbent bidder is indifferent between bidding 0 , which yields

$$
r(\pi(2)-\pi(3))+(1-r u) \pi(3)
$$

and bidding $\pi(3)$, which yields

$$
\pi(2)-\pi(3)+\frac{r}{2}(1-u) \pi(3) .
$$

Equating these two expressions yields:

$$
r=\frac{d(2)-1}{d(2)-(1+u) / 2}
$$

The expressions for the expected number of entries and the expected revenue easily follow ${ }^{44}$.

The result about revenue is immediate. For the expected number of entries, observe that

$$
\begin{gathered}
N^{\prime}(0)=-\frac{2 d(2)-3}{(2 d(2)-1)^{3}}>0, \text { for } d(2) \in\left(1, \frac{3}{2}\right) \\
N^{\prime}(1)=0, \text { and } N^{\prime \prime}(1)=\frac{1}{(d-1)^{2}}>0, \text { for } d(2)>1
\end{gathered}
$$

\footnotetext{
${ }^{44}$ The probability that an entrant acquires the first license is $(1-r)^{2}$. Whenever an entrant acquires the first license, there is sure entry on the second license when it takes place (which occurs with probability $u$ ).
} 
Proof of Proposition 4.7: Entrants have a dominant strategy, to bid $w_{e}$. Consider now an incumbent. Given the strategies of other bidders, a bid of 0 (or any other bid strictly lower than $(1-h) \bar{b})$ yields:

$$
\left[1-\left(1-q^{G T E}\right)^{n-1}\right] \pi(n)+\left(1-q^{G T E}\right)^{n-1} \pi(n+m)
$$

(When one other incumbent bids $\bar{b}$, no entrant acquires a license; when they all bid $0, m$ entrants acquire a license.)

Any bid in the range $\left((1-h) \bar{b}, \frac{w_{e}}{1-h}\right)$ is dominated by a bid of $\bar{b}$. Finally, a bid of $\bar{b}$ or higher yields:

$$
\pi(n)+v(n)-w_{e} .
$$

The last expression follows because the incumbent bidder wins then a license, no entrant is licensed, and every winner pays the entrants' bid.

The probability $q^{G T E}$ is obtained by equating expressions 6.3 and 6.4 .

\section{References}

Anton, J. and D. Yao (1992): "Coordination in Split Award Auctions," Quarterly Journal of Economics 107, 681-701.

Ausubel, L. and J. Schwartz (1999): "The Ascending Auction Paradox," discussion paper, University of Maryland.

Arrow, K. (1962): "Economic Welfare and the Allocation of Resources for Inventions," in The Rate and Direction of Inventive Activity, R. Nelson ed., Princeton University Press, Princeton.

Auriol E. and J.J. Laffont (1992): "Regulation by Duopoly," Journal of Economics and Management Strategy 1, 507-533.

Brusco, S. and G. Lopomo (1999): "Collusion via Signalling in Open Ascending Auctions with Multiple Objects and Complementarities," mimeo.

Caillaud, B. and P. Jehiel (1998): "Collusion in auctions with externalities," Rand Journal of Economics 29, 680-702.

Cameron, L., P. Cramton and R. Wilson (1997): "Using Auctions to divest generating assets," Electricity Journal 10, 22-31

Dana, J. and K. Spier (1994): "Designing a private industry," Journal of Public Economics 53, 127-147.

Farrell, J. and K. Shapiro (1990): "Horizontal mergers: an equilibrium analysis," American Economic Review 80, 107-27. 
Gale. I. and M. Stegeman (2000): "Sequential Auctions of Endogenously Valued Objects", Games and Economic Behavior, forthcoming

Gilbert, R.J. and D. Newbery (1982): "Preemptive Patenting and the Persistence of Monopoly," American Economic Review 72, 514-526.

GTE (1997): "Comments of GTE, submitted to the California Public Utilities: Auction proposal for universal service," mimeo

Harsanyi, J.C. and R. Selten (1988): A General Theory of Equilibrium Selection in Games, Cambridge, MA: MIT Press.

Katz, M. and C. Shapiro (1985): "On the Licensing of Innovations," Rand Journal of Economics 16, 504-520.

Katz, M. and C. Shapiro (1986): "How to License Intangible Property," Quarterly Journal of Economics 101, 567-590

Kamien, M (1992): "Patent Licensing," in Handbook of Game Theory, Aumann, R. and S. Hart (eds.), North-Holland, Amsterdam.

Kamien, M. and Y. Tauman (1986): "Fees versus Royalties and the Private Value of a Patent,", Quarterly Journal of Economics 101, 471-492.

Klemperer, P. (2000): "Preventing Collusion and Predation in Auction Markets," mimeo, Oxford University.

Kamien, M. , Y. Tauman and S. Oren (1992): "Optimal Licensing of Cost Reducing Innovation," Journal of Mathematical Economics 21, 483-508.

Krishna, K. (1993): "Auctions with Endogenous Valuations: The Persistence of Monopoly Revisited," American Economic Review 83, 147-160

Krishna, K. (1999): "Auctions with Endogenous Valuations: The Snowball Effect Revisited," Economic Theory 13, 377-391.

Jehiel, P. and B. Moldovanu (1995a): "Negative Externalities May Cause Delay in Negotiation", Econometrica 63, 1321-1337.

Jehiel, P. and B. Moldovanu (1995b):" Cyclical Delay in Bargaining with Externalities", Review of Economic Studies 62, 619-639.

Jehiel, P. and B. Moldovanu (1996a): "Strategic Non-Participation," RAND Journal of Economics 27, 84-98.

Jehiel, P., B. Moldovanu and E. Stacchetti (1996b): "How (not) to Sell Nuclear Weapons," American Economic Review 86, 814-829.

Jehiel, P., B. Moldovanu and E. Stacchetti (1999): "Multidimensional Mechanism Design for Auctions with Externalities," Journal of Economic Theory 85, 258-293.

Jehiel, P. and B. Moldovanu (1997): "Auction with Downstream Interaction among Buyers", RAND Journal of Economics, forthcoming.. 
Jehiel, P. and B. Moldovanu (1998): "Efficient Design with Interdependent Valuations," Econometrica, forthcoming.

Jehiel, P. and B. Moldovanu (2000b): "A Critique of the Planned Rules for the German UMTS/IMT-2000 License Auction,", discussion paper, Univesity of Mannheim.

McAfee, R.P. and J. McMillan (1996): "Analyzing the Airwaves Auction,", Journal of Economic Perspectives 10, 159-175.

McAfee, R.P. (1998): "Four Issues in Auctions and Market Design", paper presented at the Latin American Econometric Society meeting, 1997.

McAfee, R.P. and M. A. Williams (1988): "Horizontal mergers and antitrust policy," mimeo.

McGuire, T. G. and M. H. Riordan (1995): "Incomplete information and optimal market structure public purchases from private providers," Journal of Public Economics 56, 125-141.

McMillan, J. (1994): "Selling Spectrum Rights," Journal of Economic Perspectives 8, 145-162.

Milgrom, P. (1996): "Procuring Universal Service: Putting Auction Theory to Work," Lecture at the Royal Swedish Academy of Sciences, December 9.

Milgrom, P. (2000): "Putting Auction Theory to Work: The Simultaneous Ascending Auction," Journal of Political Economy 108, 245-272.

Mill, J.S. (1926): Principles of Political Economy, London: Longmans (first published in 1848)

Perry, M. K. and R. H. Porter (1985): "Oligopoly and the incentive for horizontal merger," American Economic Review 75, 219-27.

Rockett, K.E. (1990): "Choosing the Competition and Patent Licensing," RAND Journal of Economics 21, 161-171.

Rodriguez, E.G. (1997): "Auctions of Licences and Market Structure", discussion paper, Universidad Torcuato Di Tella.

Segal, I. (1999): "Contracting with Externalities," Quarterly Journal of Economics 114, 337-389.

Wilson, R. (1979): "Auctions of Shares," Quarterly Journal of Economics 93, 675-679. 


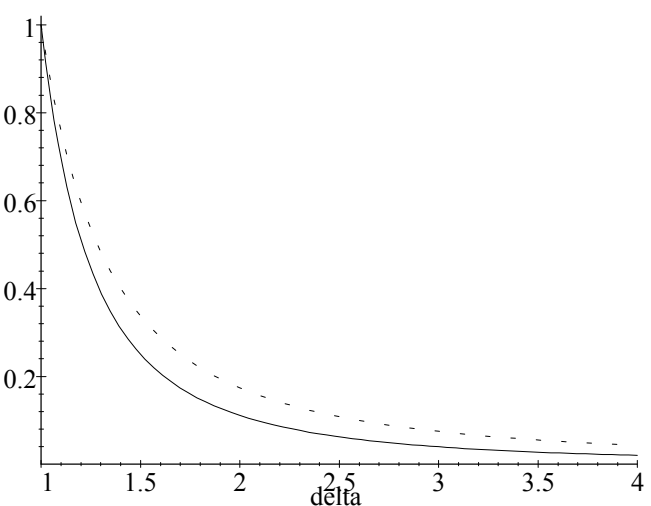

Figure 1

( $n=2$, full line; $n=3$, interrupted line )

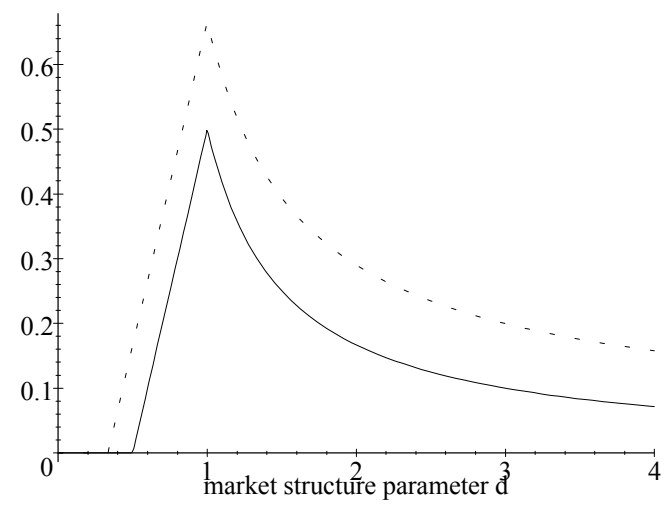

Figure 2

( $n=2$, full line; $n=3$, interrupted line ) 


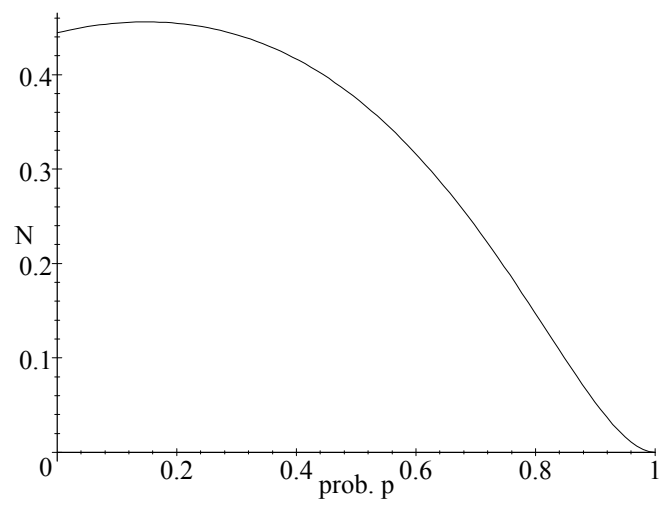

Figure 3 


\begin{tabular}{|c|c|c|}
\hline Nr. & Author & Title \\
\hline $01-27$ & $\begin{array}{l}\text { Eric Igou } \\
\text { Herbert Bless }\end{array}$ & $\begin{array}{l}\text { About the Importance of Arguments, or: Order } \\
\text { Effects and Conversational Rules }\end{array}$ \\
\hline $01-26$ & $\begin{array}{l}\text { Heiko Zuchel } \\
\text { Martin Weber }\end{array}$ & The Disposition Effect and Momentum \\
\hline $01-25$ & Volker Stocké & $\begin{array}{l}\text { An Empirical Test of the Contingency Model for } \\
\text { the Explanation of Heuristic-Based Framing-Effects }\end{array}$ \\
\hline $01-24$ & Volker Stocké & $\begin{array}{l}\text { The Influence of Frequency Scales on the Response } \\
\text { Behavior. A Theoretical Model and its Empirical } \\
\text { Examination }\end{array}$ \\
\hline $01-23$ & Volker Stocké & $\begin{array}{l}\text { An Empirical Examination of Different } \\
\text { Interpretations of the Prospect Theoryś } \\
\text { Framing-Hypothesis }\end{array}$ \\
\hline $01-22$ & Volker Stocké & $\begin{array}{l}\text { Socially Desirable Response Behavior as Rational } \\
\text { Choice: The Case of Attitudes Towards Foreigners }\end{array}$ \\
\hline $01-21$ & $\begin{array}{l}\text { Phillipe Jehiel } \\
\text { Benny Moldovanu }\end{array}$ & License Auctions and Market Structure \\
\hline $01-20$ & $\begin{array}{l}\text { Phillipe Jehiel } \\
\text { Benny Moldovanu }\end{array}$ & The European UMTS/IMT-2000 License Auctions \\
\hline 01-19 & $\begin{array}{l}\text { Arieh Gavious } \\
\text { Benny Moldovanu } \\
\text { Aner Sela }\end{array}$ & Bid Costs and Endogenous Bid Caps \\
\hline 01-18 & $\begin{array}{l}\text { Benny Moldovanu } \\
\text { Karsten Fieseler } \\
\text { Thomas Kittsteiner }\end{array}$ & Partnerships, Lemons and Efficient Trade \\
\hline 01-17 & $\begin{array}{l}\text { Raimond Maurer } \\
\text { Martin Pitzer } \\
\text { Steffen Sebastian }\end{array}$ & $\begin{array}{l}\text { Construction of a Transaction Based Real Estate } \\
\text { Index for the Paris Housing Market }\end{array}$ \\
\hline $01-16$ & Martin Hellwig & $\begin{array}{l}\text { The Impact of the Number of Participants on the } \\
\text { Provision of a Public Good }\end{array}$ \\
\hline $01-15$ & Thomas Kittsteiner & $\begin{array}{l}\text { Partnerships and Double Auctions with } \\
\text { Interdependent Valuations }\end{array}$ \\
\hline
\end{tabular}

